ANIMAL

BEHAVIOUR

\section{A hierarchy of compass systems in migratory birds}

\author{
Alexander Pakhomov ${ }^{\mathbf{1}}$ and Nikita Chernetsov ${ }^{\mathbf{1}, 2}$ \\ ${ }^{1}$ Biological Station Rybachy, Zoological Institute of the Russian Academy of Sciences, \\ ul. Pobedy, 32, Rybachy, 238535, Kaliningrad Region, Russian Federation \\ 2Department of Vertebrate Zoology, Faculty of Biology, Saint Petersburg State University, \\ Universitetskaya nab., 7-9, Saint Petersburg, 199034, Russian Federation \\ Address correspondence and requests for materials to Alexander Pakhomov, \\ sasha_p.bio@mail.ru
}

\begin{abstract}
Migratory birds use several different sources of orientation information. They have at least three compass systems based on different cues: the sun and polarized light, the stars and their constellations, and the geomagnetic field. The concurrent information obtained from these three compasses is redundant, therefore the compasses need to have a hierarchy and must be calibrated relative to each other. One of the compasses should dominate the others, or some orientation cue should be used to calibrate the remaining compass systems. Results of experiments on a variety of songbird species demonstrate that while astronomical cues calibrate the magnetic compass during the pre-migratory period, strategies used during the migratory period are more diverse. In the present review, we analyze the results of all crucial cue-conflict studies, mostly performed in nocturnal songbird migrants; we also try to understand why some migratory species calibrate their magnetic compass on sunset cues while others use the geomagnetic field or stars as a primary cue source, and we examine why the previous hypothesis could not explain the findings of all cue-conflict experiments.
\end{abstract}

Keywords: hierarchy, compass systems, compass calibration, magnetic compass, stellar compass, sun compass, orientation, migratory birds, migration.

\section{Introduction}

Billions of birds migrate from breeding grounds to wintering places and vice versa every year. To do this, according to the "map-and-compass" model proposed by Gustav Kramer in the 1950s (Kramer, 1950, 1953, 1957), they have to locate the goal of their migration without any direct sensory contact with it first (the "map" step) and then to select the direction towards that goal and maintain it during a migratory flight (the "compass" step). Most migratory birds use compass information from various sources such as the stars and their constellations (Sauer, 1957; Emlen, 1967a, 1970), the sun's position and patterns of skylight polarization (Kramer, 1957; Able, 1982; Schmidt-Koenig, 1990) and the geomagnetic field (Wiltschko and Wiltschko, 1972, 2019). Compass information obtained by birds from these cue sources can be contradictory, therefore compass systems should be calibrated with respect to a common reference system, and one of the compasses might dominate over other ones.

A review of this phenomenon was published in 2012 (Liu and Chernetsov, 2012). Since then, several new studies have been published in which researchers performed cue-conflict experiments and obtained results that did not support the hypothesis suggesting a crucial role of the sky view near the horizon proposed by Muheim et al. (2006a) and later updated in 'extended unified theory' by Sjöberg and Muheim (2016). In the present review, we tried to understand why some migratory species calibrate their magnetic compass on sunset cues, whereas 
others use the geomagnetic field or stars as a primary cue source, and why the previous hypothesis discussed below could not explain the findings of all cue-conflict experiments. We mainly focus on the relationship between the magnetic compass system and celestial cues, analyze the after-effects of exposure to cue conflict during the pre-migratory period and migrations, and briefly discuss the interrelationships between the magnetic and stellar compasses. Our predictions and analysis of this phenomenon are mostly based on experiments performed in nocturnal songbird migrants (with a notable exception of one study of waders) in which birds in experimental and control conditions were significantly oriented and showed the seasonally appropriate migratory direction in the control condition.

\section{Cue-conflict experiments}

Cue-conflict experiments are one tool of choice for studying interrelationships among the different compass systems in migratory birds. In such experiments, birds are given conflicting directional information from two or more orientation cues. This type of experiment can be divided into two groups: one is magnetic cue-conflict experiments in which the cue conflict between compass systems is organized by changing the geomagnetic field (for example, when the horizontal component of the magnetic field is rotated clockwise or counterclockwise, leaving natural celestial cues undisturbed; Fig. 1A). If manipulation of the geomagnetic field by magnetic coils is challenging (for example, if it isn't possible to buy/build relatively expensive and complicated equipment such as magnetic coils or transport them to the experimental site), one can perform celestial cue-conflict experiments. In such experiments researchers usually change the directional information from the sun (using mirrors to alter the sunset point or polarizing filters to create artificial polarization patterns, or shifting the birds' internal clock in clock-shift experiments) or stars (rotating an artificial starry sky in a planetarium) in the natural magnetic field (Fig. 1B). Magnetic field manipulation is generally preferable to manipulation of celestial cues, because it is very challenging to realistically simulate the natural polarization patterns by polarizing filters or natural starry sky in a planetarium, and it is always possible to argue that the resulting pattern is not sufficiently realistic. When birds are exposed to artificial polarized light in outdoor experiments, it is too difficult to distinguish whether the observed responses are true compass responses or simply alignments along the polarization axis or responses to artefacts produced by polarizers (Muheim, 2011). For instance, Eurasian blackcaps Sylvia atricapilla tested in Emlen funnels with polarizers responded differently to a shifted artificial e-vector produced by polarizers than to the e-vector of the natural sky (Helbig and Wiltschko, 1989).
Although the first cue-conflict experiments were performed over 50 years ago (Emlen, 1967a; Moore, 1982; Able and Cherry, 1986), and a large body of cueconflict experiment data is available for a variety of songbird migrants, it remains a subject of debate how birds calibrate their compasses and which compass system dominates over others.

\section{A hierarchy of compasses during the pre-migratory period}

Young unexperienced birds can use similar directional cues as adults: the geomagnetic field and celestial cues (the sun and stars). Both celestial compass systems are learned mechanisms: juvenile birds have to observe the sun and its movements across the sky during most parts of the day and celestial rotation during the night to develop well-functioning solar and stellar compasses, respectively (Emlen, 1967a, b, 1970; Wiltschko and Wiltschko, $1980,1981)$. In contrast to celestial compasses, the magnetic compass system in birds is believed to be innate: birds raised without access to celestial cues during ontogeny show the appropriate population-specific migratory direction in orientation experiments during their first migration (Gwinner and Wiltschko, 1978; Beck and Wiltschko, 1982; Bingman, 1983; Bletz et al., 1996). If you take garden warbler Sylvia borin nestlings from their nests at the age of 4-6 days before their eyes open, hand-raise them under an artificial rotating starry sky in a planetarium or laboratory chamber with small lights as 'stars' with and without access to the natural magnetic field (NMF) and then test birds under a stationary sky during their first migration in the absence of magnetic information, you might find an interesting fact. The birds raised by hand in the absence of proper magnetic information will be oriented towards the direction opposite to the centre of the "sky" rotation, not in the appropriate migratory direction, in contrast to the birds that had access to NMF before (Weindler et al., 1996). Results of this study indicate that the magnetic field (and the magnetic compass itself) plays a crucial role in the proper development of stellar orientation during ontogeny. In subsequent experiments, the same research team found an additional key element of star compass development: not only the presence of magnetic information but also the direction of celestial rotation was essential for this process (Weindler et al., 1997).

It might mean that if only the magnetic compass can allow birds to choose the correct migratory direction and magnetic information is crucial for development of stellar orientation, this compass system takes a higher position in the compass hierarchy during the pre-migratory period (before the first migration in a bird's life) than others. However, there is an opposite situation in the interrelationships between the magnetic and celes- 
(A)

Cue-conflict exposure

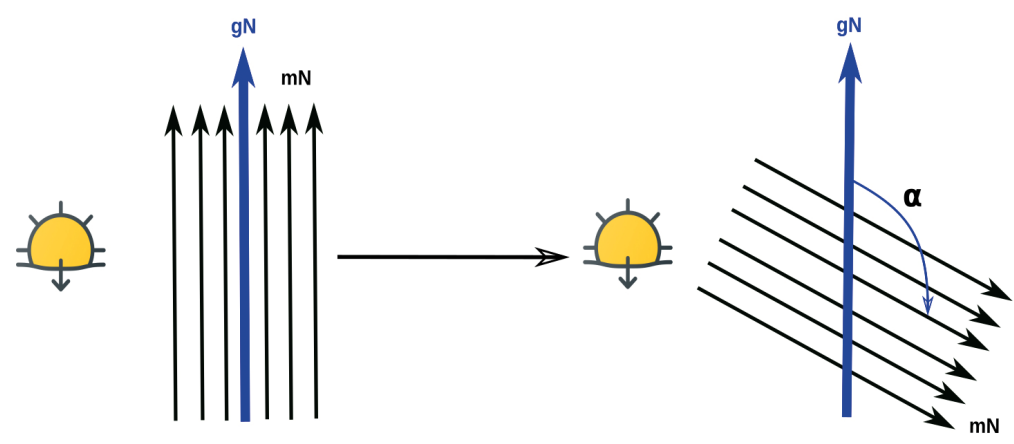

Orientation tests

Control condition

After the cue-conflict

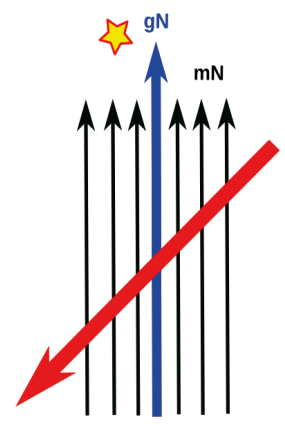

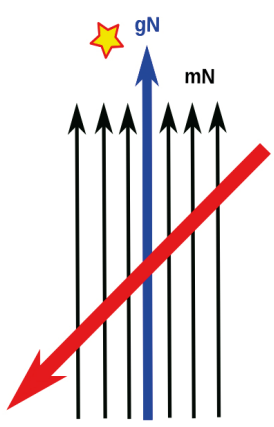

No recalibration of the magnetic compass

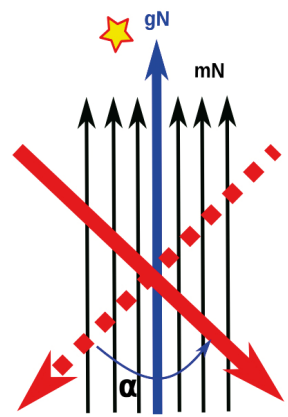

The magnetic compass is calibrated by celestial cues

(B)

Cue-conflict exposure
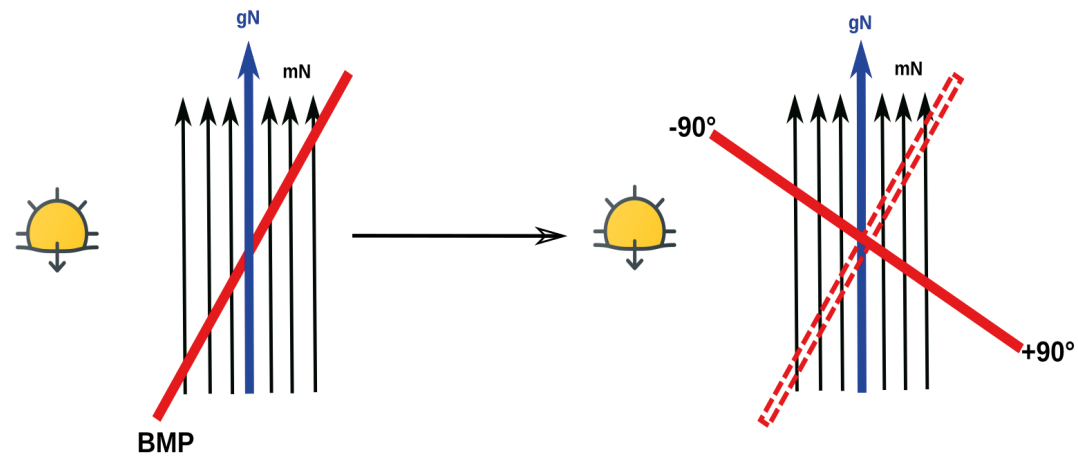

Orientation tests

\section{Control condition}

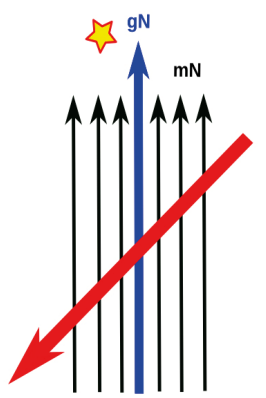

After the cue-conflict
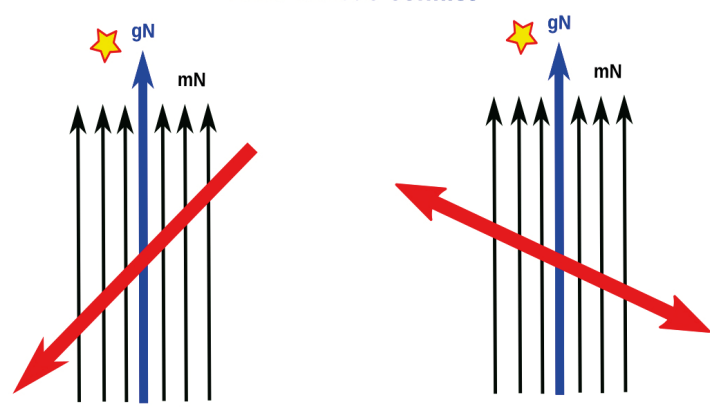

No recalibration of the magnetic compass
The magnetic compass is calibrated by polarized light cues

Fig. 1. Cue-conflict treatments: A) Celestial cue-conflict experiments in which we manipulate information from celestial cues, for example, polarized light; B) Magnetic cue-conflict experiments in which cue conflict between compass systems is made by changing the geomagnetic field (for example, when the horizontal component of the magnetic field is rotated clockwise or anticlockwise). A blue arrow is a direction to geographic North ( $\mathrm{gN})$, black arrows are magnetic lines and direction to magnetic North (mN), BMP is the band of maximum polarization, a red arrow indicates the direction of birds' activity in Emlen funnels or vanishing bearing of free-flying birds with lightsticks or radio-transmitters. Each test consists of two phases: the first one is cue-conflict treatment, the second one is an orientation test immediately after the first phase or the following day after the cue conflict. 
tial compasses. If you expose young birds to the cue conflict between celestial and magnetic compasses before the onset of their first migration and then analyze their orientation during the autumn migratory period, celestial cues will have a priority over magnetic cues and will calibrate the magnetic compass. This has been shown in experiments on both medium- and long-distance songbird migrants, e.g., Savannah sparrows Passerculus sandwichensis in North America, European robins Erithacus rubecula and pied flycatchers Ficedula hypoleuca in Europe (Bingman, 1983; Able and Able 1990a, b; Prinz and Wiltschko, 1992; Alert et al., 2015). Interestingly, the sun itself is not involved in the calibration process. If juvenile Savannah sparrows are exposed to a cue conflict (shifted magnetic field + natural sky all day) but have no access to polarized light by a pseudodepolarizer before the start of migration and then are tested indoors during migration, they do not show any signs of recalibration of the magnetic compass in these orientation tests. The birds that have access to natural polarized skylight during cue conflict calibrated their magnetic compass relative to polarization patterns (Able and Able, 1993). Similar results have been obtained in experiments with polarizing filters without direct access to the sun during cue conflict (Able and Able, 1995a). All of these findings indicate that polarized skylight is necessary to produce calibration of the magnetic compass during the pre-migratory period.

\section{A hierarchy of compasses during the migratory season}

In contrast to the hierarchy of compass systems during the pre-migratory season, when celestial cues dominate the magnetic compass in various songbird migrants from different continents, compass calibration is more diverse during migration. There are three possible different strategies which birds can exhibit in cue-conflict experiments: 1) the magnetic compass is used to calibrate celestial compasses (Fig. 2A); 2) birds use celestial cues to calibrate the magnetic compass as they do during the pre-migratory season (Fig. 2B); 3) simple dominance of one of the compass systems (stellar or magnetic; Fig. 2C).

\section{1) Magnetic cues calibrate celestial compasses}

Theoretically, the magnetic compass system can be a more stable cue source than others for birds during migration. Firstly, near the poles the angle of inclination (a parameter of the magnetic field which changes from $0^{\circ}$ at the magnetic equator to $90^{\circ}$ at the magnetic poles) becomes increasingly steep, so it could be difficult for birds at high latitudes to use their magnetic compass based on the inclination of magnetic field lines as a primary compass system. However, outdoor experi- ments near the North Pole and lab tests in an artificial magnetic field showed that birds were able to orient in a field with $85^{\circ}$ and higher inclination (Åkesson et al., 2001; Lefeldt et al., 2015). Secondly, the magnetic compass sense is an inherited feature of birds, in contrast to celestial compass systems which need to be learned: juvenile birds learn celestial rotation around the North Star and constellations typical of the northern hemisphere during ontogeny (Emlen, 1967a, 1970). However, it must be taken into account that the stellar sky changes when birds move south during autumn migration: the North Star gets lower and becomes more difficult to see, northern stars and their constellations disappear and new southern stars appear in the sky. The geomagnetic field also changes in such a journey and migratory birds reach regions where the intensity of the field is lower than in their breeding grounds and possibly falls outside of the functional window of the magnetic compass (Wiltschko, 1978). However, birds are able to adapt to previously unexperienced intensities of the magnetic field during migration, according to laboratory and virtual displacement experiments (Fransson et al., 2001; Wiltschko et al., 2006; Winklhofer et al., 2013; Bulte et al., 2017). Another problem is that the magnetic compass cannot be used near the magnetic equator where the inclination is close to $0^{\circ}$ (Wiltschko and Wiltschko, 1972; Wiltschko, 1974; Schwarze et al., 2016). The sun can also be an unreliable cue source for migrating birds because its position above the horizon depends on seasons and geographic position, and celestial cues are not available in overcast conditions.

Many results of previous cue-conflict experiments have indicated the precedence of magnetic cues when birds were exposed to a shifted magnetic field and tested in orientation cages at the same time. They showed a corresponding shift in direction of orientation, immediately during tests or with some delay, as shown in European robins by Wiltschko and Wiltschko (1975b), and ignored information from celestial cues during both migratory seasons (Wiltschko and Wiltschko, 1975a; Wiltschko et al., 1998; Sandberg et al., 2000, 2002; Bingman and Wiltschko, 2010). Birds exposed to cue conflict (an artificial magnetic field + natural celestial cues) and then tested in orientation experiments (in Emlen funnels or release with lightsticks that allowed visual tracking of their flight for a limited period of time) continued to exhibit shifted orientation when they had access to all natural orientation cues (Sandberg et al., 2000; Åkesson et al., 2002; Table 1A 7-10) or only to celestial cues (Wiltschko et al., 1998, 1999; 2001 Table 1A 1, 2, 4). If migrants are tested with only the magnetic field available as an orientation cue after exposure to cue conflict, their orientation does not differ from control birds exposed to the natural magnetic field and natural celestial cues during the cue conflict (Wiltschko et al., 1999, 2008; 


\section{Natural condition}

(A)<smiles></smiles>

$\mathrm{gN}$

$\mathrm{mN}$<smiles>c1ccc(C2CCCCC2)cc1</smiles>

(B)

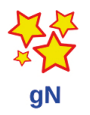

$\mathrm{mN}$

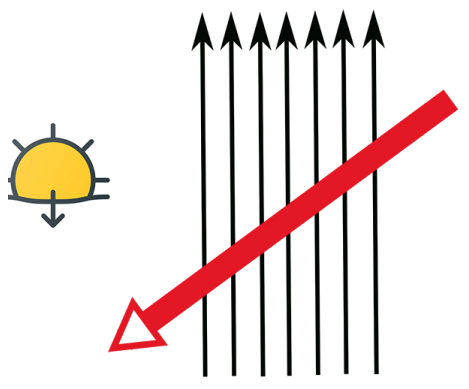

(C)

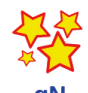

gN

$\mathrm{mN}$

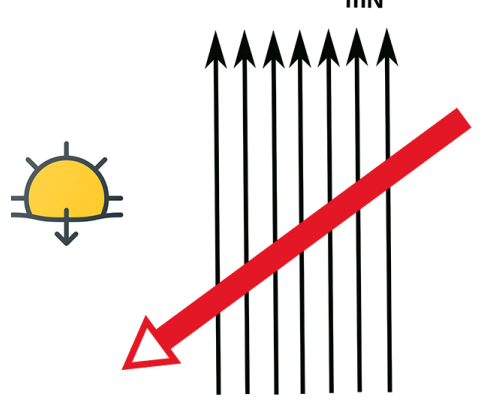

\section{During cue-conflict treatment}

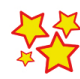

gN
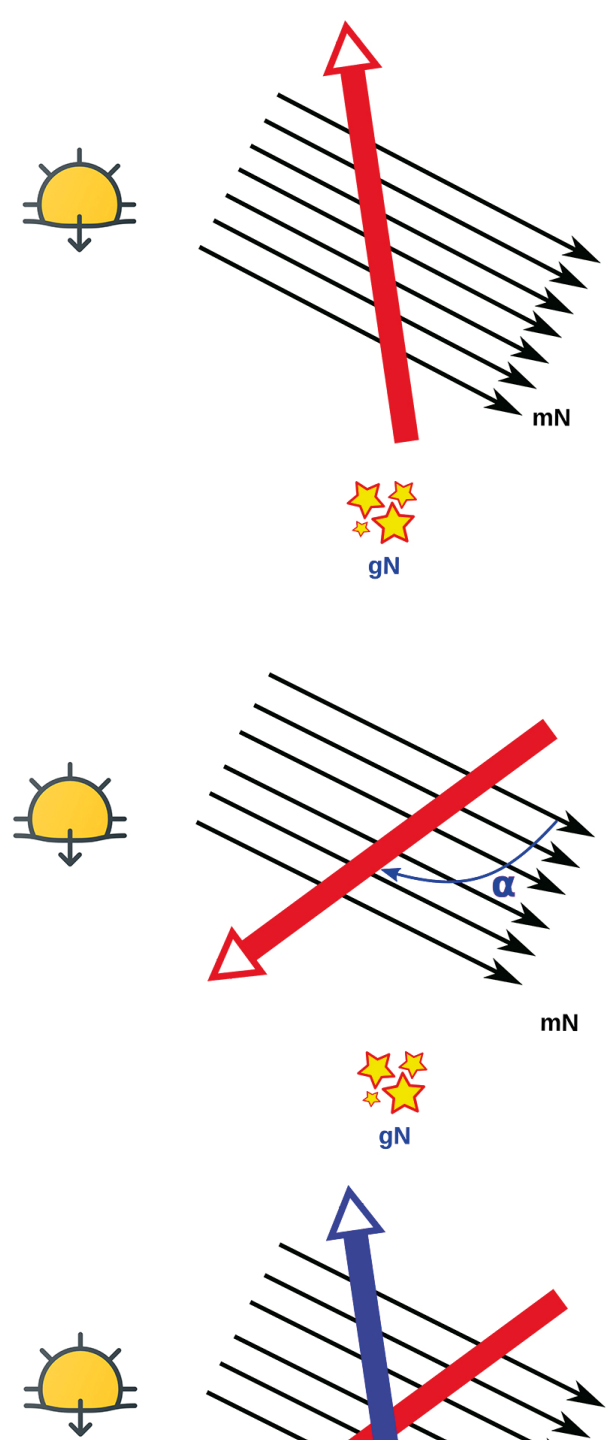

gN

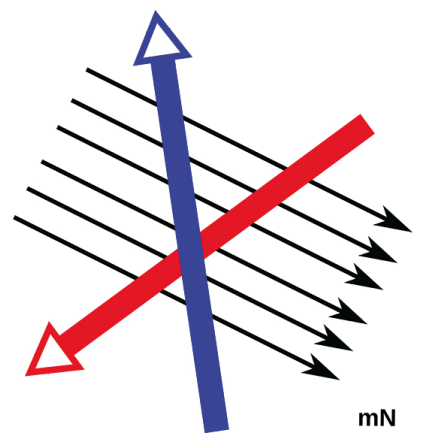

After cue-conflict treatment
(release/Emlen funnel tests)

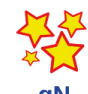

gN
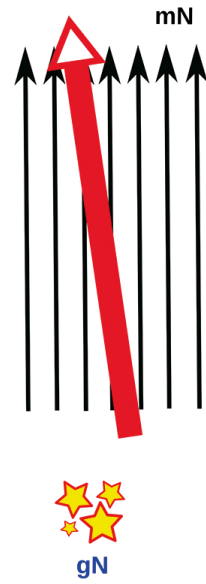

$\mathrm{mN}$

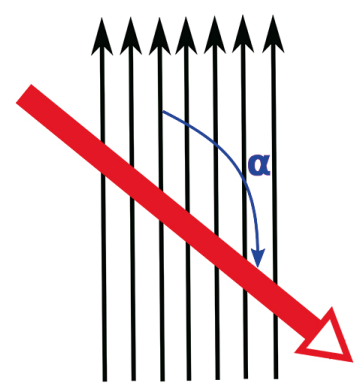

证落

gN

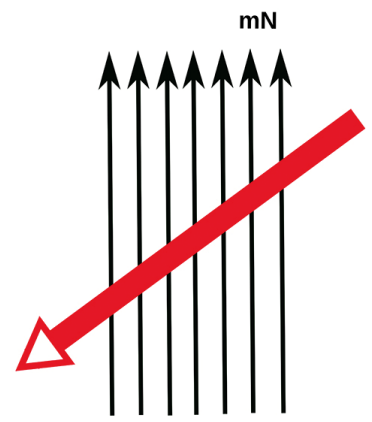

Fig. 2. Three types of responses to cue-conflict treatments in migratory birds, when exposed to changed magnetic field (-120 horizontally turned) under natural clear sky during autumn migration: A) Magnetic cues calibrate celestial compasses; B) Celestial cues calibrate the magnetic compass; C) The stellar or the magnetic cues are used separately without transferring information to other compasses (simple dominance of one cue, from Chernetsov et al., 2011). The black arrows represent the horizontal direction of (geo)magnetic field (the direction to magnetic North), the red arrow represents the expected direction of the birds, the blue arrow represents the expected direction of the birds if they use the magnetic compass as a primary cue reference ( $C$, cue-conflict phase). The circle with rays indicates the position of the setting sun, the stars represent unchanged direction information from the stellar cues (the direction to geographic North), mN — magnetic North, gN — geographic North. 
Table 1A 3, 5). Additionally, researchers discovered an interesting fact for species that migrate during twilight periods: birds did not transfer information about cue conflict between natural polarized light and an altered magnetic field from sunset to sunrise (Wiltschko et al., 2001). All these findings suggest that the magnetic compass provides the primary reference system for these songbird migrants and calibrates celestial compasses.

\section{2) Celestial cues calibrate the magnetic compass}

The first cue-conflict experiment that contradicted the apparently coherent pattern mentioned above and showed another type of dominance among compass systems during migrations was the study on a North American medium-distance migrant, the Savannah sparrow (Able and Able, 1995). Both juvenile and adult birds changed the direction of their activity in Emlen funnels after several days and nights in the cue-conflict condition in a way that indicated that their magnetic compass was calibrated by celestial cues. Currently, many studies show that celestial cues calibrate the magnetic compass. Most of them were performed in North American songbird migrants, e.g., Swainson's thrush Catharus ustulatus and grey-cheeked thrush C.minimus, white-crowned sparrow Zonotrichia albicollis and Savannah sparrow (Cochran et al., 2004; Muheim et al., 2006b, 2007, 2009; Table 1B 11-16). The only study that showed similar interrelationships among the different compass systems in European migrants was that by Guinchi et al. (2015, Table 1B 17) who replicated their previous experiments in pied flycatchers (Gaggini et al., 2010; Table 1C 18). Interestingly, these authors obtained contradictory results using two different methods to analyze the orientation of birds after the cue conflict: birds tested outdoors in Emlen funnels in the days following cue-conflict treatment showed recalibration of the magnetic compass by the polarized light sun-related pattern. When the same birds were released with radio-transmitters after being tested in Emlen funnels, they vanished in the appropriate migratory direction, suggesting stellar dominance in free-flying birds. The authors supposed that the magnetic compass of pied flycatchers in their tests was calibrated by polarized light, but when birds were released with radio-transmitters they ignored the magnetic information immediately after release and only relied on their unshifted star compass. However, there is no evidence that this species uses only the stellar compass during nocturnal migratory flight and ignores the information from the geomagnetic field. Additionally, in other cueconflict experiments, pied flycatchers tested in Emlen funnels immediately after cue-conflict treatment with access to all cues during the cue conflict and orientation tests showed the same response to such treatmentthey ignored the conflict between celestial cues and the magnetic field and oriented in an appropriate migratory direction (Rabøl, 2010; Pakhomov et al., 2019). It should be kept in mind that orientation tests in studies by Guinchi et al. (2015; and in many others, see Table 1 ) were performed around sunset, so one cannot be certain that birds showed true migratory orientation behaviour, even if they oriented in the appropriate seasonal direction (Pakhomov and Chernetsov, 2014). Telemetry studies in songbird migrants during autumn passage demonstrated that in the wild most species begin their migratory flights within 1-2 h after sunset (Åkesson et al., 1996; Bolshakov and Chernetsov, 2004; Schmaljohann et al., 2013b; Müller et al., 2018; but see Bolshakov et al., 2007 for medium-distance migrants). Similar results have been shown in radar studies (Schmaljohann et al., 2007). All of these findings may indicate that pied flycatchers do not calibrate their magnetic compass relative to celestial cues at sunset and show simple dominance of stellar or magnetic compasses as shown in a previous paper of this research group (Gaggini et al., 2010).

One of the most interesting and convincing studies which showed the priority of celestial cues over magnetic ones was that by Cochran et al. (2004). In this study, North American thrushes were exposed to cue conflict [natural celestial cues and an artificial magnetic field identical to the natural geomagnetic field (NMF) but rotated $80^{\circ}$ clockwise $(\mathrm{CW})$ ] from the local sunset until the end of nautical twilight and after that immediately released with radio-transmitters. When the birds were released, they found themselves in the NMF and flew $80^{\circ}$ counterclockwise (CCW) of their typical migratory direction, in contrast to the control birds kept in the NMF before release. During the next night, they changed their flight direction back to the normal one. Several thrushes that did not start their migratory flight on the first night and remained at the release site during the next few days also flew in their seasonally appropriate migratory direction.

Results of this very convincing and methodologically clean study suggest several important conclusions. Firstly, these North American thrushes use the magnetic compass as their primary compass system during nocturnal migratory flight and calibrate it using information from the sun and/or polarized light during sunset. If possible, they perform this calibration daily. Secondly, it seems that celestial cues such as stars and constellations do not play an important role in orientation of these species and are very low in the hierarchy of compass systems. Possibly, birds only use the star compass when they are denied access to other orientation cues such as the magnetic field or the sun and polarized light (Mouritsen, 1998; Zapka et al., 2009; Pakhomov et al., 2017), or some species do not use the full set of independent compass systems, with the star compass either not available in some species or consequently ignored 
by them (Pakhomov and Chernetsov, 2014; Chernetsov, 2015).

Trying to explain why some songbird migrants use celestial cues to calibrate the magnetic compass and other ones calibrate their sun compass relative to the geomagnetic field, Muheim et al. (2006a) reviewed many previous cue-conflict experiments and found an interesting pattern: if birds have access to an undisturbed sky view, including part of the sky near the horizon, they use information from celestial cues during sunset as primary cues. If they cannot see the sky near the horizon during cue-conflict experiments due to testing in Emlen funnels or at times of day that do not include sunset or sunrise, they use the geomagnetic field as a primary cue and calibrate their celestial compass systems relative to a magnetic reference. This idea had been mooted in one of the previous orientation studies for the first time (Sandberg, 1991). The authors of the review also suggested how polarized light at sunset and/or sunrise can be used by birds as a cue source to calibrate their magnetic compass. It occurs only at sunset or sunrise and not in other times of the day because the band of maximum polarization (the BMP) and e-vector pass directly through the zenith and are aligned vertically to the horizon at that time (Fig. 3; Muheim et al., 2006b). In this condition, birds do not need to see sunset or sunrise points to determine their position because they can use the intersection of the BMP with the horizon to deduce the sunset/sunrise point, even if they have access only to a partial view of the sky. Intersections of the BMP and the horizon at sunset and sunrise are independent of topography, season and horizon height. Migratory birds could theoretically average the intersections of the BMP with the horizon at sunrise and sunset at the same place and use this bisector of directions as the North-South axis at any location and time of year (Fig. 3c; Muheim et al., 2007; Liu and Chernetsov, 2012).

Muheim et al. (2006b, 2007; Table 1B 14-15) performed cue-conflict experiments in juvenile and adult Savannah sparrows to test the hypothesis mentioned above. In these studies, they exposed wild-caught birds to a $\pm 90^{\circ}$ shifted polarization pattern at sunrise or sunset with access to an undisturbed magnetic field and a full view of the sky near the horizon. However, this simple and elegant idea could not be proven in these studies due to some methodological pitfalls: if birds average their orientation using information from the BMP at sunset and sunrise, after being exposed to polarization patterns shifted by $90^{\circ}$, they should shift their orientation by $45^{\circ}$ (Liu and Chernetsov, 2012) and not by $90^{\circ}$ as shown by Muheim et al. (2006b). Muheim et al. (2007) tested birds in different experimental conditions (polarization pattern shifted by $90^{\circ}$ at sunrise and sunset with view vs. without view of the horizon) trying to show that view of the sky near the horizon is a crucial factor for recalibrating the magnetic compass relative to the information from celestial cues. However, Wiltschko et al. (2008) pointed out a methodological issue in this study: after testing in control conditions, birds were chosen for the next step of experiments to the cue conflict if they were oriented to the southeast (the assumed migratory direction) $\pm 90^{\circ}$; in other words, the control group of Savannah sparrows was not oriented in a seasonally appropriate migratory direction before the cue-conflict experiments. It is not correct to use these birds for further testing, because selecting a subsample of birds that are by chance oriented in the 'right' direction from a group that is not significantly oriented as a whole, does not create a sample which can be assumed to be oriented.

To address the criticism by Wiltschko et al. (2008), in which the authors tested Australian silvereyes in a changed magnetic field and did not find any links between recalibration of the magnetic compass by celestial cues and the sky view near the horizon at sunset, Muheim et al. (2009) carried out new experiments with juvenile and adult white-throated sparrows (Zonotrichia albicollis; Table 1B 16). They exposed birds to a $+90^{\circ}$ shifted magnetic field and a $\pm 90^{\circ}$ shifted polarization pattern at sunrise and/or sunset and obtained the same results (dominance of celestial cues) after the cue conflict as were recorded for Savannah sparrows (Muheim et al. 2006b, 2007). However, studies performed by Muheim and co-authors (2006b, 2007, 2009) have shown a crucial role of polarization pattern in recalibration of the magnetic compass in Savannah and whitethroated sparrows, despite some methodological issues mentioned above.

\section{3) Simple dominance of one of compass systems}

Most of the well-done experimental studies and reviews about the hierarchy of compass systems in migratory birds and compass calibration were published before 2010 and included results of experiments mostly performed with North American songbird migrants (Able, 1993; Able and Able, 1995b; Wiltschko et al., 1998, 2008; Åkesson et al., 2002; Cochran et al., 2004; Muheim et al., 2006a, b, 2009). All of them showed the priority of magnetic or skylight polarization compasses and recalibration of other ones, using different cue-conflict techniques (magnetic field or polarization pattern manipulation) and orientation tests (Emlen funnels or radio telemetry). However, a new kind of interrelationship among compass systems has been discovered in the last decade, i.e., simple dominance of one of the compasses without recalibration (Fig. 2C). The studies by Gaggini et al. (2010) and Rabøl (2010) showed that European migrants (pied flycatchers and redstarts Phoenicurus phoenicurus, Table 1C 18, 19,21) did not calibrate their compass systems. In the latter study, the same research 
(A)
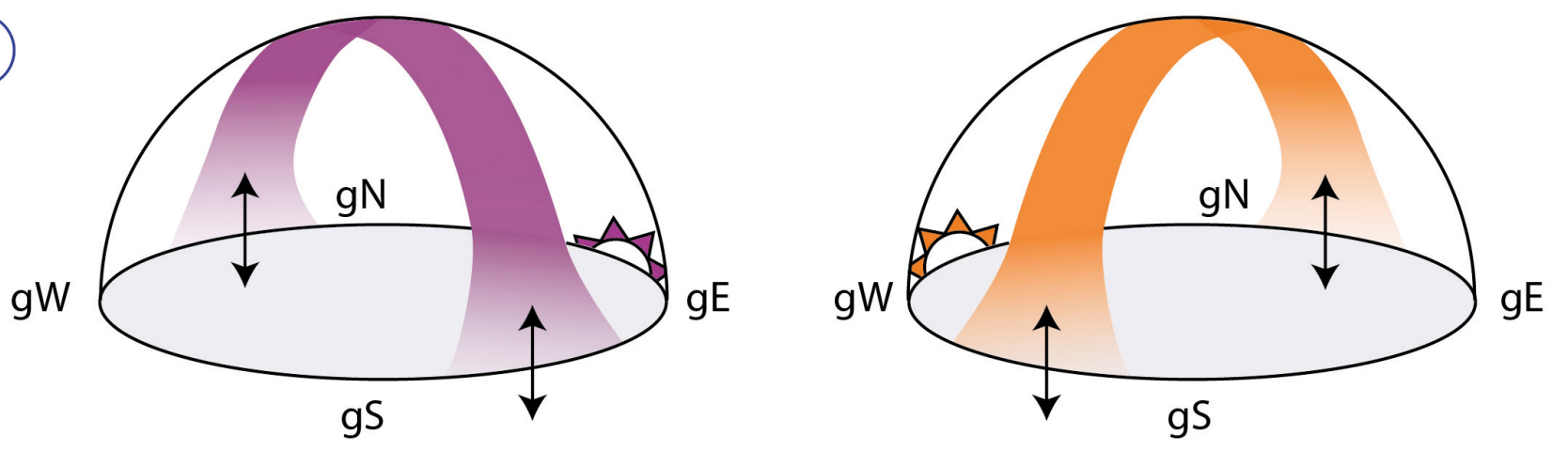

B
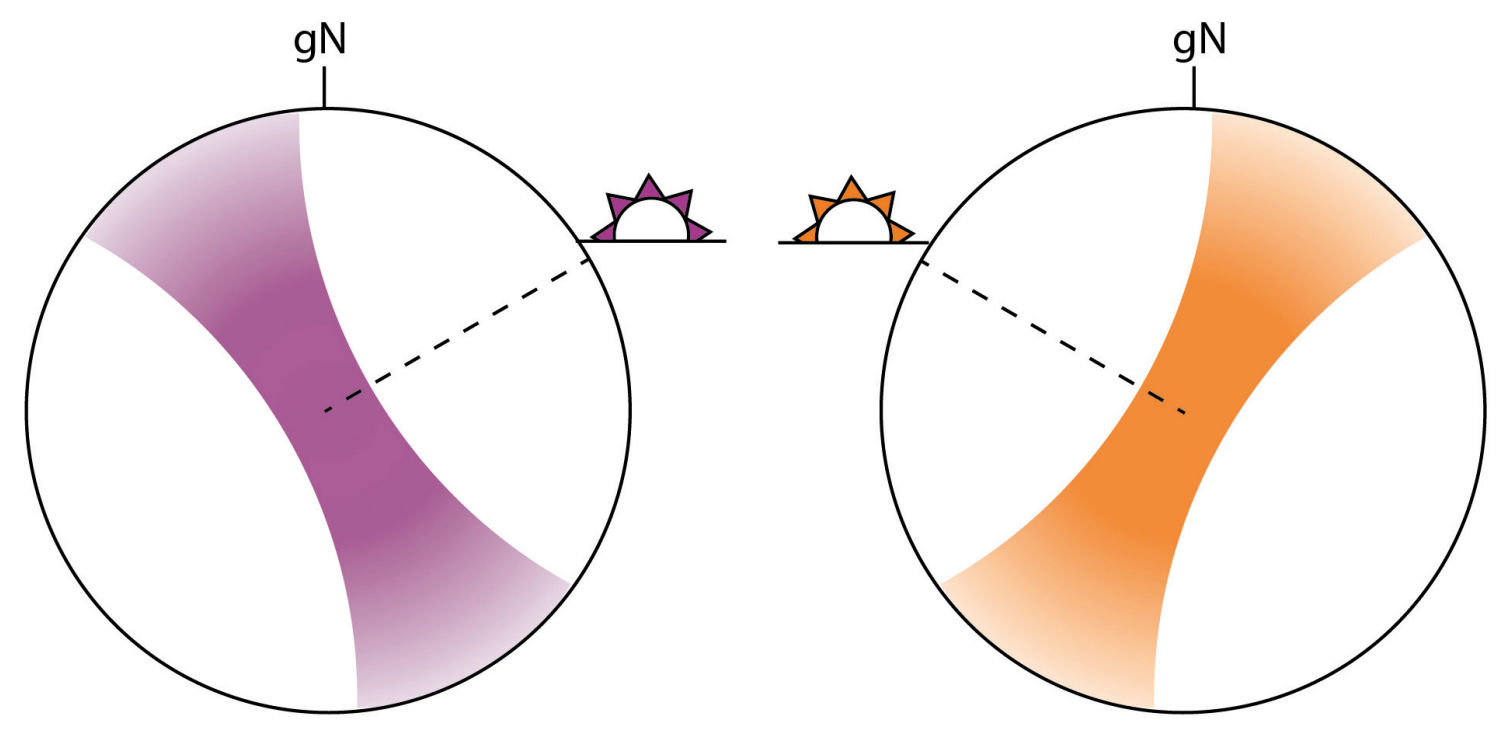

(c)

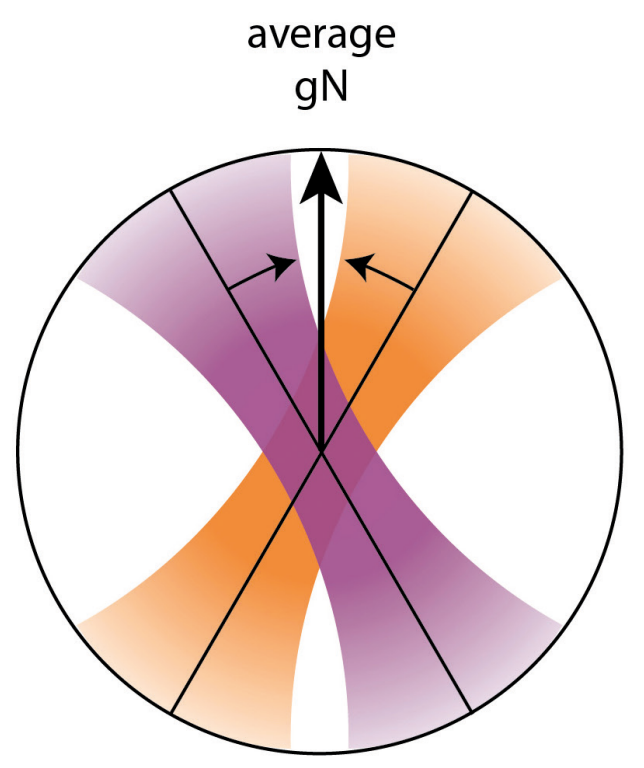

Fig. 3. Three- and two-dimensional representation of the band of maximum polarization (BMP) at sunrise ( $a$ and $b$, left) and sunset ( $a$ and $b$, right). Averaging of sunrise and sunset calibration provides the birds with a true geographical reference, which is independent of latitude and season (c). gN, gS, gW and gE are geographic North, South, West and East, respectively (from Muheim, 2011, with changes). 


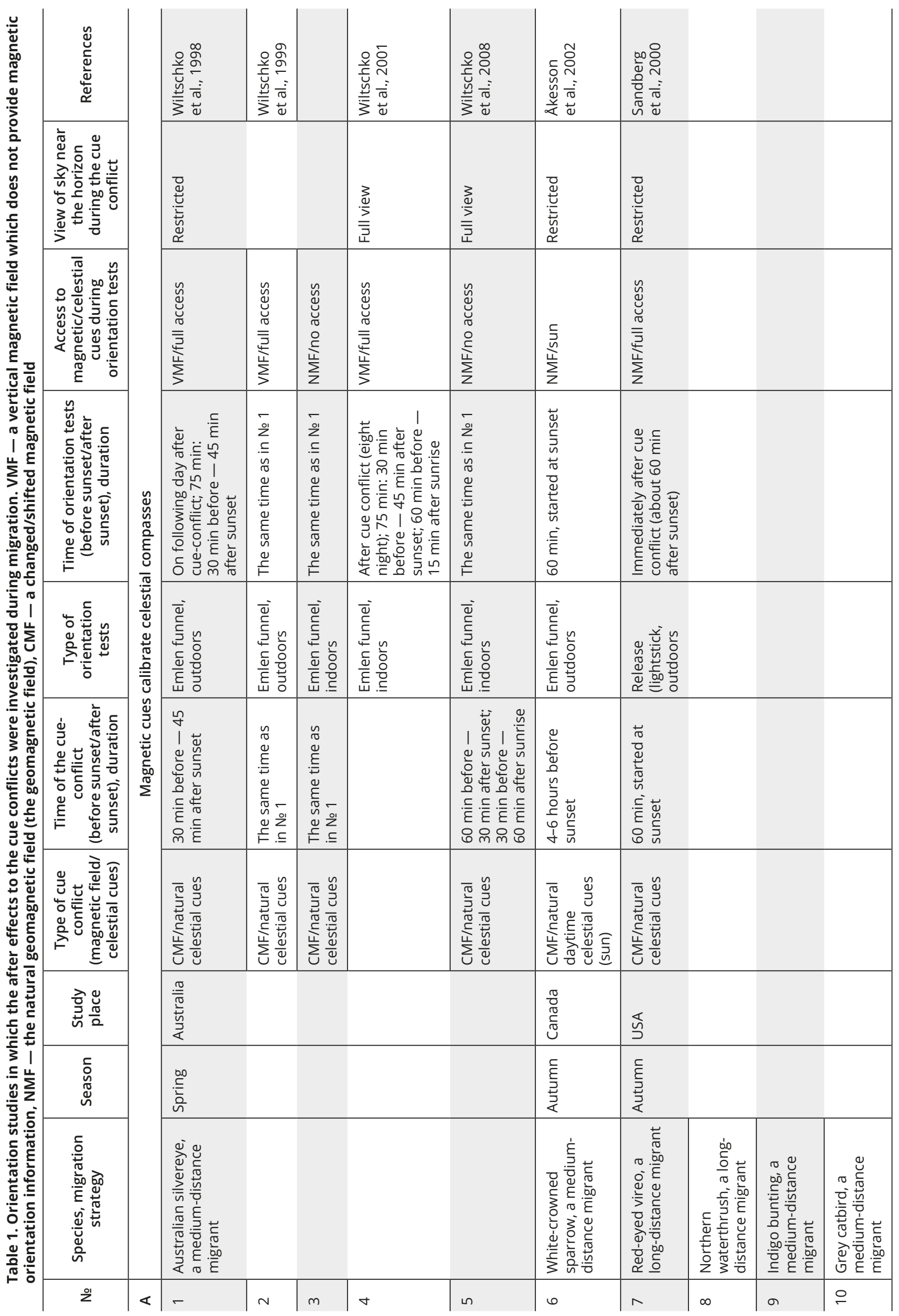




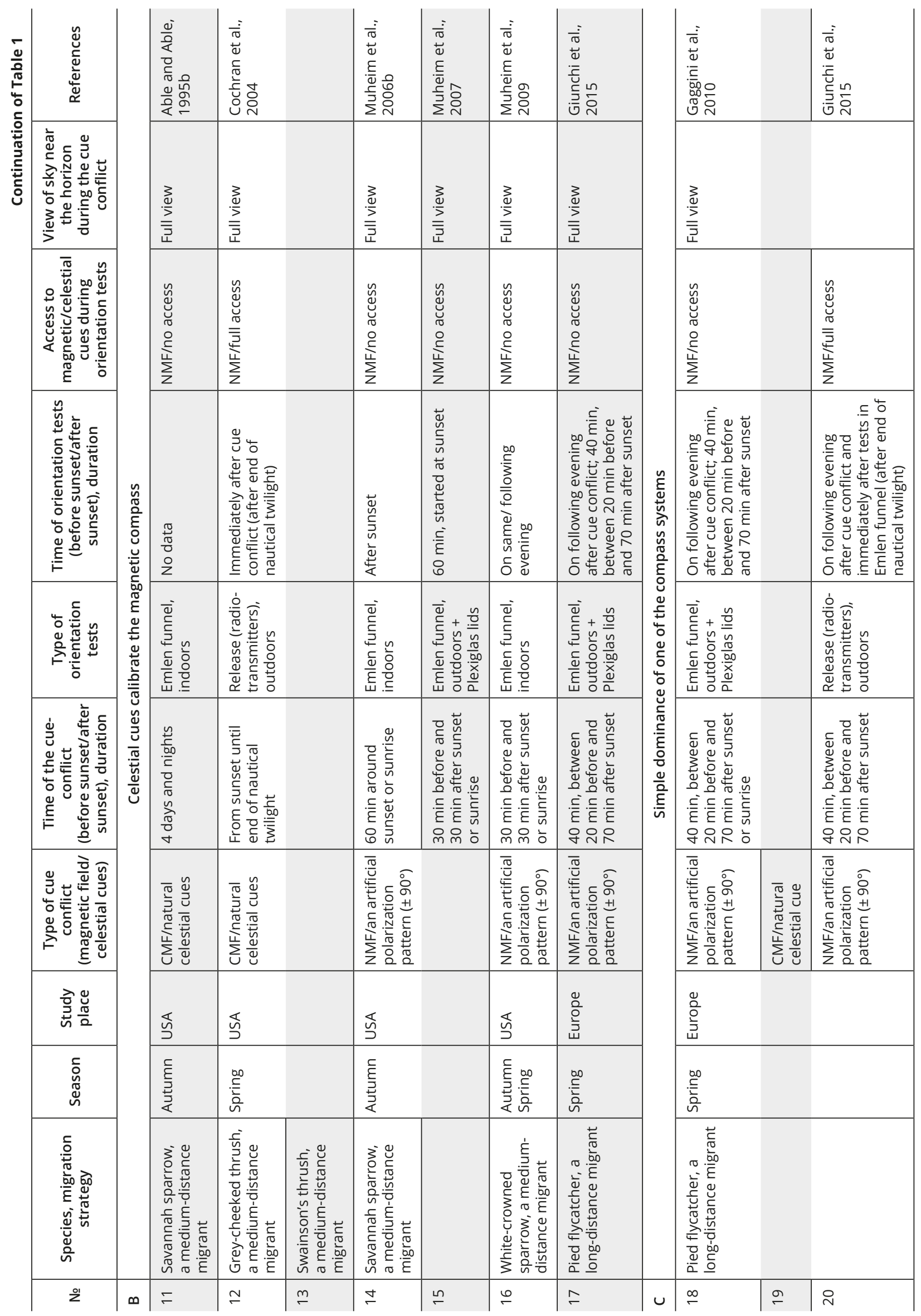




\begin{tabular}{|c|c|c|c|c|c|}
\hline 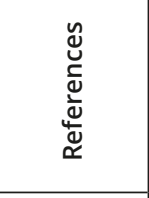 & 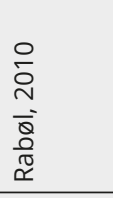 & 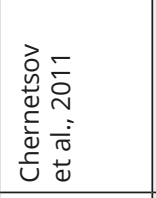 & 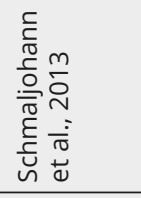 & 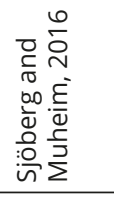 & 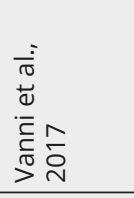 \\
\hline 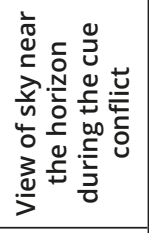 & $\frac{3}{\frac{3}{3}}$ & $\begin{array}{l}\frac{3}{2} \\
\overline{3} \\
\end{array}$ & $\begin{array}{l}\frac{3}{0} \\
\overline{1} \\
\end{array}$ & $\frac{3}{\frac{3}{3}}$ & $\frac{3}{\frac{3}{2}}$ \\
\hline 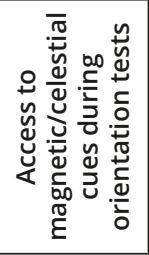 & 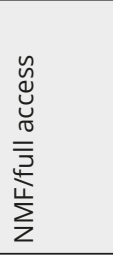 & 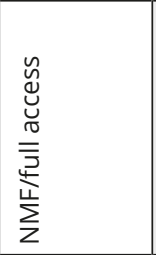 & 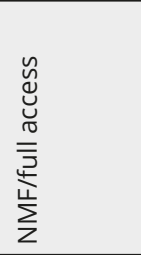 & 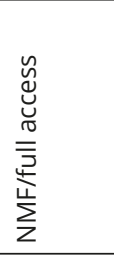 & 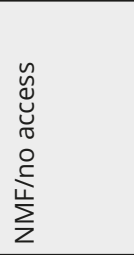 \\
\hline 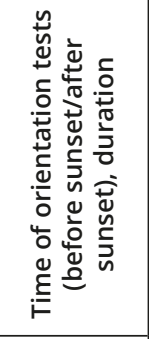 & 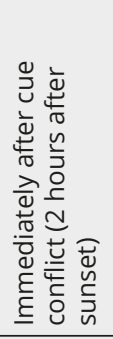 & 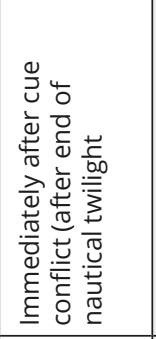 & 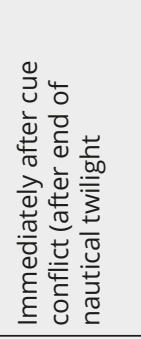 & 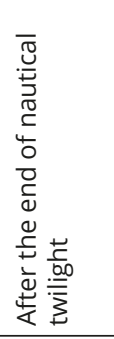 & 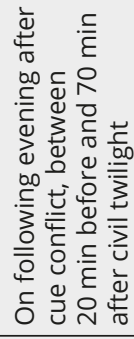 \\
\hline 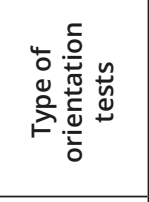 & 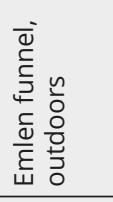 & 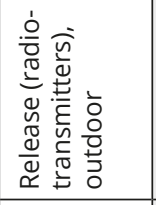 & 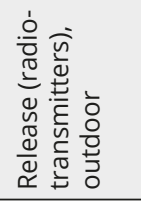 & 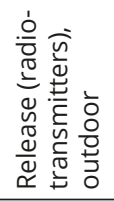 & 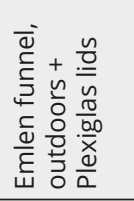 \\
\hline 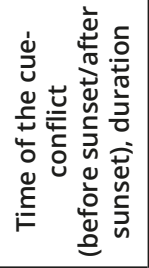 & 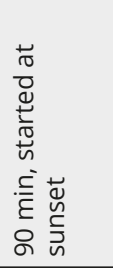 & 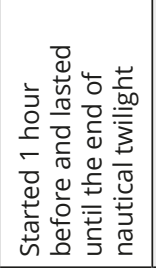 & 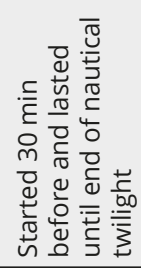 & 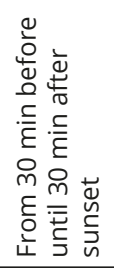 & 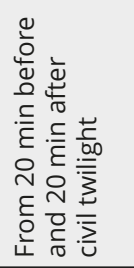 \\
\hline 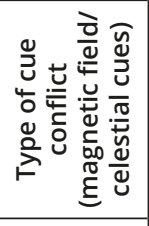 & 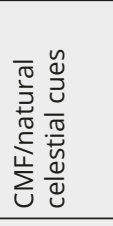 & 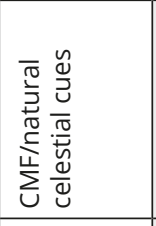 & 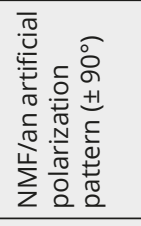 & 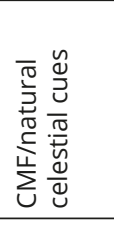 & 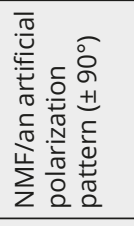 \\
\hline $\begin{array}{l}\text { 흘 } \\
\text { 总 } \\
\frac{\pi}{\alpha}\end{array}$ & 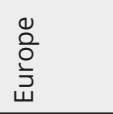 & $\begin{array}{l}\stackrel{0}{0} \\
\stackrel{0}{0} \\
\overline{\vec{\nu}}\end{array}$ & 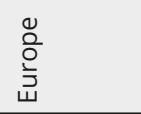 & 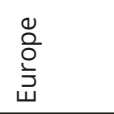 & 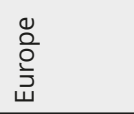 \\
\hline 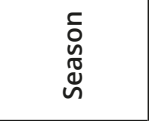 & 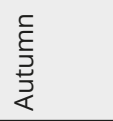 & 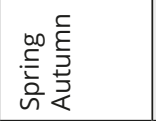 & 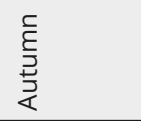 & 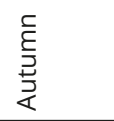 & 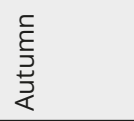 \\
\hline 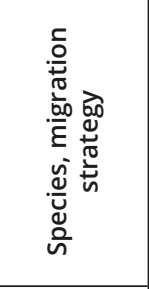 & 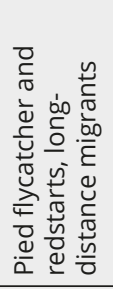 & 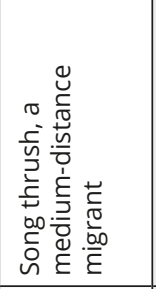 & 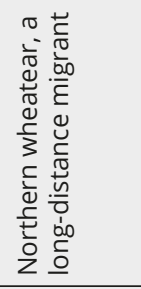 & 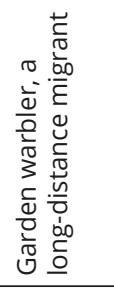 & 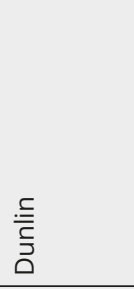 \\
\hline$\stackrel{20}{2}$ & $\bar{v}$ & $\approx$ & $\stackrel{m}{\sim}$ & $\stackrel{ \pm}{N}$ & $\stackrel{n}{N}$ \\
\hline
\end{tabular}


team reported contradictory results in pied flycatchers (Giunchi et al., 2014): birds recalibrated their magnetic compass on sunset cues after exposure to \pm 90 shifted polarization pattern when tested in Emlen funnels on the following day after the cue conflict (Table 1B 17), but not after being released with radio transmitters (Table 1C 20). We discussed this study in the previous part of the review.

The study by Chernetsov et al. (2011) was an attempt to replicate the work of Cochran et al. (2004) in a medium-distance European species, the song thrush Turdus philomelos (Table 1C 21). Before being released with radio tags, the birds were exposed to $120^{\circ}$ clockwise/anticlockwise shifted magnetic field with the full view of the sky near the horizon during spring and autumn migration. It was the first study in which cue-conflict experiments were performed in the same species during both migratory seasons. Song thrushes in this experiment did not show any type of compass calibration and any response to pre-exposure to the deflected magnetic field during either autumn or spring migration. Similar results (simple dominance of magnetic or stellar compass) were obtained in several studies carried out in other European migratory birds: northern wheatears Oenanthe oenanthe in a radio-tracking study (Schmaljohann et al., 2013; Table 1C 22) and dunlins Calidris alpina tested in circular arenas (Vanni et al., 2017; Table 1C 25) after being exposed to $\pm 90^{\circ}$ shifted polarization pattern did not calibrate their compass systems and were oriented in the seasonal migratory direction in autumn.

A recent study by Sjöberg and Muheim (2016) in a long-distance songbird migrant, the garden warbler, showed that orientation of free-flying warblers was not affected by pre-exposure to $+90^{\circ}$ deflected magnetic field for 1 hour around sunset, and this species did not calibrate its compass systems either (Table 1C 24). Trying to explain the results of experiments in this study and all previous contradictory data obtained with other migratory birds, they suggested a new hypothesis, an 'extended unified theory'. According to this scheme, if the view of the BMP near the horizon and nearby landmarks are not available at sunset or sunrise, migratory birds temporarily transfer the previously calibrated magnetic information to available celestial compasses and recalibrate them. Conversely, if birds have access to the polarization pattern near the horizon and a full view of landmarks at sunrise/sunset, they fully (the BMP is visible at both sunset and sunrise) or provisionally (the BMP is visible only at sunrise or sunset) recalibrate their magnetic compass by information from polarized light. When the stars become visible, the birds recalibrate the star compass with respect to the previously recalibrated magnetic compass. However, such star compass recalibration only takes place if stars and their constellations are available during the cue-conflict treatment
(Sjöberg and Muheim, 2016). This assumption, as the authors suggest, can explain why their garden warblers, pied flycatchers in the study by Guinchi et al. (2015) and northern wheatears by Schmaljohann et al. (2013) did not show recalibration of any compasses. In these studies stars were not visible during the cue conflict between the BMP and the magnetic compass and there was not cue conflict between the stellar and magnetic compasses when birds were released with radio tags; therefore, birds simply relied on the previously recalibrated stellar compass. However, firstly, as already mentioned, there is no direct evidence that these songbird migrants use the stellar compass but not the magnetic one during nocturnal flights (Chernetsov, 2015). Secondly, this theory cannot explain the results of the study by Chernetsov et al. (2011), in which birds had access to the BMP and landmarks at sunset during the cue conflict and then were released after the stars appeared in the sky but birds did not show any type of calibration. The suggestion by Sjöberg and Muheim (2016) that it could be the topographic bias in the departure direction of song thrushes released on the Courish Spit is not tenable, because the data from another release site in mainland Kaliningrad region showed the same departure direction after release (Chernetsov et al., 2011). Additionally, according to the Rayleigh sky model, the BMP becomes broader and blurrier when moving towards the horizon at sunset and sunrise (Fig. 3; Cronin et al., 2006; Hamaoui, 2017; Eshelman and Shaw, 2019), so it could be difficult to use the BMP as a calibration cue in the way proposed by Muheim et al. (2006a) and Sjöberg and Muheim (2016).

\section{Concluding remarks}

Obviously, the interrelationship between compass systems among various species of migratory birds during migration is complicated, in contrast to the pre-migratory season. Much data obtained in the rapidly growing number of cue-conflict experiments during the two recent decades changed the opinion of the scientific community about this phenomenon from "birds calibrate their celestial compasses with respect to information from the geomagnetic field" to "various species calibrate their celestial compasses by the magnetic compass and vice versa" after studies on North American thrushes (Cochran et al., 2004), Savannah sparrows and whitecrowned sparrows (Muheim et al., 2007, 2009). Trying to explain these contradictory results, a new theory was suggested by Muheim et al. (2006a), but it was not supported by the latest studies performed especially in European migratory birds, in which birds had access to both the BMP and landmarks near the horizon but did not show any type of calibration (i.e., simple dominance of celestial or magnetic compasses; Gaggini et al., 2010; Chernetsov et al., 2011; Schmaljohann et al., 2013; Sjö- 
berg and Muheim, 2016; Vanni et al., 2017). Another possibility mentioned by Susanne Åkesson during her talk at the 7th Royal Institute of Navigation 2011 conference "Orientation and Navigation. Birds, Humans and Other Animals" in Reading, UK is that the difference in the hierarchy of compass systems between North American and European species might be explained by the variation of parameters of the geomagnetic field (e.g., declination) that birds could expect to encounter during their migration in North America but not in Europe (Liu and Chernetsov, 2012). However, the latest calculation of variation of the geomagnetic field in North America and Europe performed by Sjöberg and Muheim (2016) did not support this assumption. Another explanation - that long-distance migrants generally need a capacity for more precise orientation and have to calibrate their compass systems, whereas shortand medium-distance migrants may reach their wintering and breeding areas using only one compass without calibration and survive even if their compass systems sometimes might be wrong by ca. $5^{\circ}$ or more - is not supported by studies in which both long- and mediumdistance migrants showed simple dominance of one of the compasses (Rabøl, 2010; Chernetsov et al., 2011; Schmaljohann et al., 2013; Sjöberg and Muheim, 2016; Vanni et al., 2017). The newest 'extended unified theory' is rather complicated and cannot explain the results of some studies (Wiltschko et al., 2008; Chernetsov et al., 2011). The reason may be that a uniform solution that could explain results of all cue-conflict experiments in migrating birds might not exist. A more parsimonious explanation of the variable results obtained by different authors in different avian species might be that the compass system hierarchy differs between the species of migrants, or maybe even between populations within one species. For some species or populations in North America and Europe, the magnetic compass is in a higher position in the hierarchy of compass systems and is used to calibrate other compasses, but for other species this hierarchy might be different. There likely is no uniform rule or theory that could explain to us why some species calibrate their celestial compasses relative to magnetic cues and vice versa or rely on one of the compasses without any type of calibration during migration. We think that each species (or even population) "chooses" its own calibration strategy and this choice does not depend on migratory strategy (short- or long-distance migration), seasons, variations of magnetic field parameters, access to the BMP and landscapes near the horizon, etc.

\section{Acknowledgements}

The reported study was supported by a grant from the Russian Foundation for Basic Research 19-14-50676 to A.P. The authors acknowledge support from the Zoological Institute RAS (Research Project AAAA-A19-119021190073-8). The au- thors are most grateful to Ekaterina Chernetsova, who redrew Figure 3. The authors are most grateful to anonymous reviewers for their comments on earlier drafts of this manuscript.

\section{References}

Able, K. P. 1982. Skylight polarization patterns at dusk influence migratory orientation in birds. Nature 299:550-551. https://doi.org/10.1038/299550a0

Able, K.P. 1993. Orientation cues used by migratory birds: A review of cue-conflict experiments. Trends in Ecology and Evolution 8:367-371. https://doi.org/10.1016/01695347(93)90221-A

Able, K. P. and Cherry, J. D. 1986. Mechanisms of dusk orientation in white-throated sparrows (Zonotrichia albicollis): clock-shift experiments. Journal of Comparative Physiology A 159:107-113. https://doi.org/10.1007/BF00612501

Able, K. P. and Able, M. A. 1990a. Calibration of the magnetic compass of a migratory bird by celestial rotation. Nature 347:378-379. https://doi.org/10.1038/347378a0

Able, K. P. and Able, M. A. 1990b. Ontogeny of migratory orientation in the savannah sparrow, Passerculus sandwichensis: Mechanisms at sunset. Animal Behaviour 39:11891198. https://doi.org/10.1016/S0003-3472(05)80791-2

Able, K. P. and Able, M. A. 1993. Daytime calibration of magnetic orientation in a migratory bird requires a view of skylight polarization. Nature 364:523-525. https://doi. org/10.1038/364523a0

Able, K. P. and Able, M. A. 1995a. Manipulations of polarized skylight calibrate magnetic orientation in a migratory bird. Journal of Comparative Physiology A 177:351-356. https://doi.org/10.1007/BF00192423

Able, K. P. and Able, M. A. 1995b. Interactions in the flexible orientation system of a migratory bird. Nature 375:230232. https://doi.org/10.1038/375230a0

Åkesson S., Alerstam T., and Hedenström A. 2006. Flight initiation of nocturnal passerine migrants in relation to celestial orientation conditions at twilight. Journal of Avian Biology 27:95-102. https://doi.org/10.2307/3677138

Åkesson, S., Morin, J., Muheim, R., and Ottosson, U. 2001. Avian orientation at steep angles of inclination: experiments with migratory white-crowned sparrows at the magnetic North Pole. Proceedings of the Royal Society $B$ 268:1907-1913. https://doi.org/10.1098/rspb.2001.1736

Åkesson, S., Morin, J., Muheim, R., and Ottosson, U. 2002. Avian orientation: Effects of cue-conflict experiments with young migratory songbirds in the high Arctic. Animal Behaviour 64:469-475. https://doi.org/10.1006/ anbe.2002.3077

Alert, B., Michalik, A., Thiele, N., Bottesch, M., and Mouritsen, H. 2015. Re-calibration of the magnetic compass in hand-raised European robins (Erithacus rubecula). Scientific Reports 5:14323. https://doi.org/10.1038/srep14323

Beck, W. and Wiltschko, W. 1982. The magnetic-field as a reference system for genetically encoded migratory direction in pied flycatchers (Ficedula hypoleuca Pallas). Zeitschrift für Tierpsychologie 60:41-46. https://doi. org/10.1111/j.1439-0310.1982.tb01075.x

Bingman, V.P. 1983. Magnetic field orientation of migratory Savannah sparrows with different first summer experience. Behaviour 87:43-52. https://doi. org/10.1163/156853983X00110

Bingman, V. P. and Wiltschko, W. 2010. Orientation of Dunnocks (Prunella modularis) at sunset. Ethology 77:1-9. https://doi.org/10.1111/j.1439-0310.1988.tb00187.x

Bletz, H., Weindler, P., Wiltschko, R., Wiltschko, W., and Berthold, P. 1996. The magnetic field as reference for the 
innate migratory direction in blackcaps, Sylvia atricapilla. Naturwissenschaften 83:430-432. https://doi. org/10.1007/s001140050313

Bolshakov, C. and Chernetsov, N. 2004. Initiation of nocturnal flight in two species of long-distance migrants (Ficedula hypoleuca and Acrocephalus schoenobaenus) in spring: a telemetry study. Avian Ecology and Behaviour 12:63-76.

Bolshakov, C., Chernetsov, N., Mukhin, A., Bulyuk, V., Kosarev, V., Ktitorov, P., Leoke, D., and Tsvey, A. 2007. Time of nocturnal departures in European robins, Erithacus rubecula, in relation to celestial cues, season, stopover duration and fat score. Animal Behaviour 74:855-865. https://doi.org/10.1016/j.anbehav.2006.10.024

Bulte, M., Heyers, D., Mouritsen, H., and Bairlein, F. 2017. Geomagnetic information modulates nocturnal migratory restlessness but not fueling in a long distance migratory songbird. Journal of Avian Biology 48:75-82. https://doi. org/10.1111/jav.01285

Chernetsov, N. 2015. Avian compass systems: Do all migratory species possess all three? Journal of Avian Biology 46:342-343. https://doi.org/10.1111/jav.00593

Chernetsov, N., Kishkinev, D., Kosarev, V., and Bolshakov, C. 2011. Not all songbirds calibrate their magnetic compass from twilight cues: A telemetry study. Journal of Experimental Biology 214:2540-2543. https://doi.org/10.1242/ jeb.057729

Cochran, W. W., Mouritsen, H., and Wikelski, M. 2004. Migrating songbirds recalibrate their magnetic compass daily from twilight cues. Science 304:405-408. https://doi. org/10.1126/science.1095844

Cronin, T.W., Warrant, E.J., and Greiner, B. 2006. Celestial polarization patterns during twilight. Applied Optics 45:5582-5589. https://doi.org/10.1364/AO.45.005582

Emlen, S. T. 1967a. Migratory orientation in the Indigo bunting, Passerina cyanea. Part I: Evidence for use of celestial cues. The Auk 84:309-342. https://doi.org/10.2307/4083084

Emlen, S. T. 1967b. Migratory orientation in the Indigo bunting, Passerina cyanea. Part II: Mechanism of celestial orientation. The Auk 84:463-489. https://doi. org/10.2307/4083330

Emlen, S. T. 1970. Celestial rotation: its importance in the development of migratory orientation. Science 170:11981201. https://doi.org/10.1126/science.170.3963.1198

Eshelman, L. M. and Shaw, J. A. 2019. Visualization of all-sky polarization images referenced in the instrument, scattering, and solar principal planes. Optical Engineering 58(8):082418. https://doi.org/10.1117/1.OE.58.8.082418

Fransson, T., Jakobsson, S., Johansson, P., Kullberg, C., Lind, J., and Vallin, A. 2001. Magnetic cues trigger extensive refuelling. Nature 414:35-36. https://doi. org/10.1038/35102115

Gaggini, V., Baldaccini, N. E., Spina, F., and Giunchi, D. 2010. Orientation of the pied flycatcher Ficedula hypoleuca: Cue-conflict experiments during spring migration. Behavioral Ecology and Sociobiology 64:1333-1342. https:// doi.org/10.1007/s00265-010-0948-6

Giunchi, D., Vanni, L., Baldaccini, N. E., Spina, F., and Biondi, F. 2015. New cue-conflict experiments suggest a leading role of visual cues in the migratory orientation of Pied Flycatchers Ficedula hypoleuca. Journal of Ornithology 156:113-121. https://doi.org/10.1007/s10336-0141107-z

Gwinner, E. and Wiltschko, W. 1978. Endogenously controlled changes in migratory direction of the garden warbler, Sylvia borin. Journal of Comparative Physiology 125:267273. https://doi.org/10.1007/BF00656605

Hamaoui, M. 2017. Polarized skylight navigation. Applied Optics 56(3):37-46. https://doi.org/10.1364/AO.56.000B37
Helbig, A. J. and Wiltschko, W. 1989. The skylight polarization patterns at dusk affect the orientation behavior of blackcaps, Sylvia atricapilla. Naturwissenschaften 76:227-229. https://doi.org/10.1007/BF00627697

Kramer, G. 1950. Weitere Analyse der Faktoren, welche die Zugaktivität des gekäfigten Vogels orientieren. Naturwissenschaften 37:377-378. https://doi.org/10.1007/ BF00626007

Kramer, G. 1953. Wird die Sonnenhöhe bei der Heimfindeorientierung verwertet? Journal für Ornithologie 94:201219. https://doi.org/10.1007/BF01922508

Kramer, G. 1957. Experiments on bird orientation and their interpretation. Ibis 99:196-227. https://doi.org/10.1111/ j.1474-919X.1957.tb01947.x

Lefeldt, N., Dreyer, D., Schneider, N.-L., Steenken, F., and Mouritsen, H. 2015. Migratory blackcaps tested in Emlen funnels can orient at 85 degrees but not at 88 degrees magnetic inclination. Journal of Experimental Biology 218:206-211. https://doi.org/10.1242/jeb.107235

Liu, X. and Chernetsov, N. 2012. Avian orientation: multi-cue integration and calibration of compass systems. Chinese Birds 3:1-8. https://doi.org/10.5122/cbirds.2012.0001

Moore, F. R. 1982. Sunset and the orientation of a nocturnal bird migrant: A mirror experiment. Behavioral Ecology and Sociobiology 10:153-155. https://doi.org/10.1007/ BF00300176

Mouritsen, H. 1998. Redstarts, Phoenicurus phoenicurus, can orient in a true-zero magnetic field. Animal Behaviour 55:1311-1324. https://doi.org/10.1006/anbe.1997.0696

Muheim, R., Moore, F. R., and Phillips, J. B. 2006a. Calibration of magnetic and celestial compass cues in migratory birds - a review of cue-conflict experiments. Journal of Experimental Biology 209:2-17. https://doi.org/10.1242/ jeb.01960

Muheim, R., Phillips, J. B., and Åkesson, S. 2006b. Polarized light cues underlie compass calibration in migratory songbirds. Science 313:837-839. https://doi.org/10.1126/ science.1129709

Muheim, R., Åkesson, S., and Phillips, J. B. 2007. Magnetic compass of migratory Savannah sparrows is calibrated by skylight polarization at sunrise and sunset. Journal of Ornithology 148:485-494. https://doi.org/10.1007/ s10336-007-0187-4

Muheim, R., Phillips, J.B., and Deutschlander, M.E. 2009. White-throated sparrows calibrate their magnetic compass by polarized light cues during both autumn and spring migration. Journal of Experimental Biology 212:3466-3472. https://doi.org/10.1242/jeb.032771

Muheim, R. 2011. Behavioural and physiological mechanisms of polarized light sensitivity in birds. Philosophical Transactions of the Royal Society B 366:763-771. https://doi. org/10.1098/rstb.2010.0196

Müller, F., Eikenaar, C., Crysler, Z. J., Taylor, P. D., and Schmaljohann, H. 2018. Nocturnal departure timing in songbirds facing distinct migratory challenges. Journal of Animal Ecology 87:1102-1115. https://doi.org/10.1111/13652656.12821

Pakhomov, A. and Chernetsov, N. 2014. Early evening activity of migratory Garden Warbler Sylvia borin: Compass calibration activity? Journal of Ornithology 155:621-630. https://doi.org/10.1007/s10336-014-1044-x

Pakhomov, A., Anashina, A., and Chernetsov, N. 2017. Further evidence of a time-independent stellar compass in a night-migrating songbird. Behavioral Ecology and Sociobiology 71:48. https://doi.org/10.1007/s00265-017-2279-3

Pakhomov, A., Anashina, A., and Chernetsov, N. 2019. No evidence for compass calibration in European songbird migrants during both migratory seasons. Abstracts of 12th 
European Ornithologists' Union Congress (EOU 2019), 26-30 August 2019, Cluj Napoca, Romania, p. 112.

Prinz, K. and Wiltschko, W. 1992. Migratory orientation of pied flycatchers: interaction of stellar and magnetic information during ontogeny. Animal Behaviour 44:539-545. https://doi.org/10.1016/0003-3472(92)90063-F

Rabøl, J. 2010. Orientation by passerine birds under conflicting magnetic and stellar conditions: no calibration in relation to the magnetic field. Dansk Ornithologisk Forenings Tidsskrift 104:85-102.

Sandberg, R. 1991. Sunset orientation of robins, Erithacus rubecula, with different fields of sky vision. Behavioral Ecology and Sociobiology 28:77-83. https://doi.org/10.1007/ BF00180983

Sandberg, R., Bäckman, J., Moore, F. R., and Lõhmus, M. 2000. Magnetic information calibrates celestial cues during migration. Animal Behaviour 60:453-462. https://doi. org/10.1006/anbe.2000.1582

Sandberg, R., Moore, F. R., Bäckman, J., and Lõhmus, M. 2002. Orientation of nocturnally migrating Swainson's Thrush at dawn and dusk: importance of energetic condition and geomagnetic cues. The Auk 119:201-209. https://doi. org/10.1093/auk/119.1.201

Sauer, F. 1957. Die Sternenorientierung nächtlich ziehender Grasmücken. Zeitschrift für Tierpsychologie 14:20-70.

Schmaljohann, H., Rautenberg, T., Muheim, R., Naef-Daenzer, B., and Bairlein, F. 2013a. Response of a free-flying songbird to an experimental shift of the light polarization pattern around sunset. Journal of Experimental Biology 216:1381-1387. https://doi.org/10.1242/jeb.080580

Schmaljohann, H., Korner-Nievergelt, F., Naef-Daenzer, B., Nagel, R., Maggini, I., Bulte, M., and Bairlein, F. 2013b. Stopover optimization in a long-distance migrant: the role of fuel load and nocturnal take-off time in Alaskan northern wheatears (Oenanthe oenanthe). Frontiers in Zoology 10:26. https://doi.org/10.1186/1742-9994-10-26

Schmidt-Koenig, K. 1990. The sun compass. Experientia 46:336-342. https://doi.org/10.1007/BF01952166

Schwarze, S., Steeken, F., Thiele, N., Kobylkov, D., Nefeldt, N., Dreyer, D., Schneider, N.-L., and Mouritsen, H. 2016. Migratory blackcaps can use their magnetic compass at 5 degrees inclination, but are completely random at 0 degrees inclination. Scientific Reports 6:33805. https:// doi.org/10.1038/srep33805

Sjöberg, S. and Muheim, R. 2016. A new view on an old debate: Type of cue-conflict manipulation and availability of stars can explain the discrepancies between cue-calibration experiments with migratory songbirds. Frontiers in Behavioral Neuroscience 10:1-12. https://doi. org/10.3389/fnbeh.2016.00029

Vanni, L., Baldaccini, N. E., and Giunchi, D. 2017. Cue-conflict experiments between magnetic and visual cues in dunlin Calidris alpina and curlew sandpiper Calidris ferruginea. Behavioral Ecology and Sociobiology 71:1-9. https:// doi.org/10.1007/s00265-017-2290-8

Weindler, P., Wiltschko, R., and Wiltschko, W. 1996. Magnetic information affects the stellar orientation of young bird migrants. Nature 383:158. https://doi. org/10.1038/383158a0

Weindler, P., Baumetz, M., and Wiltschko, W. 1997. The direction of celestial rotation influences the development of stellar orientation in young garden warblers (Sylvia borin). Journal of Experimental Biology 200:2107-2113.
Wiltschko, W. 1974. Der magnetkompass der gartengrasmücke (Sylvia borin). Journal für Ornithologie 115:1-7. https://doi.org/10.1007/BF01647313

Wiltschko, W. 1978. Further analysis of the magnetic compass of migratory birds. In: Animal migration, navigation, and homing. pp. 302-310. https://doi.org/10.1007/978-3662-11147-5_29

Wiltschko, W. and Wiltschko, R. 1972. Magnetic compass of European robins. Science 176:62-64. https://doi. org/10.1126/science.176.4030.62

Wiltschko, W. and Wiltschko, R. 1975a. The interaction of stars and magnetic field in the orientation system of night migrating birds. I. Autumn experiments with European warblers (Gen. Sylvia). Zeitschrift für Tierpsychologie 37:337355. https://doi.org/10.1111/j.1439-0310.1975.tb00885.x

Wiltschko, W. and Wiltschko, R. 1975b. The interaction of stars and magnetic field in the orientation system of night migrating birds. II. Spring experiments with European robins (Erithacus rubecula). Zeitschrift für Tierpsychologie 39:265-282. https://doi.org/10.1111/j.1439-0310.1975. tb00912.x

Wiltschko, R. and Wiltschko, W. 1980. The process of learning sun compass orientation in young homing pigeons. Naturwissenschaften 67:512-514. https://doi. org/10.1007/BF01047636

Wiltschko, R. and Wiltschko, W. 1981. The development of sun compass orientation in young homing pigeons. Behavioral Ecology and Sociobiology 9:135-141. https://doi. org/10.1007/BF00293584

Wiltschko, R. and Wiltschko, W. 2019. Magnetoreception in birds. Journal of the Royal Society Interface 16:20190295. https://doi.org/10.1098/rsif.2019.0295

Wiltschko, W., Wiltschko, R., Munro, U., and Ford, H. 1998. Magnetic versus celestial cues: Cue-conflict experiments with migrating silvereyes at dusk. Journal of Comparative Physiology A 182:521-529. https://doi.org/10.1007/ s003590050199

Wiltschko, R., Munro, U., Ford, H., and Wiltschko, W. 1999. After-effects of exposure to conflicting celestial and magnetic cues at sunset in migratory silvereyes Zosterops $I$. lateralis. Journal of Avian Biology 30:56-62. https://doi. org/10.2307/3677243

Wiltschko, W., Stapput, K., Thalau, P., and Wiltschko, R. 2006. Avian magnetic compass: Fast adjustment to intensities outside the normal functional window. Naturwissenschaften 93:300-304. https://doi.org/10.1007/s00114006-0102-5

Wiltschko, R., Munro, U., Ford, H., and Wiltschko, W. 2008. Contradictory results on the role of polarized light in compass calibration in migratory songbirds. Journal of Ornithology 149:607-614. https://doi.org/10.1007/ s10336-008-0324-8

Winklhofer, M., Dylda, E., Thalau, P., Wiltschko, W., and Wiltschko, R. 2013. Avian magnetic compass can be tuned to anomalously low magnetic intensities. Proceedings of the Royal Society B 280:20130853. https://doi. org/10.1098/rspb.2013.0853

Zapka, M., Heyers, D., Hein, C. M., Engels, S., Schneider, N. L., Hans, J., Weiler, S., Dreyer, D., Kishkinev, D., Wild, J. M., and Mouritsen, H. 2009. Visual but not trigeminal mediation of magnetic compass information in a migratory bird. Nature 461:1274-1277. https://doi.org/10.1038/nature08528 